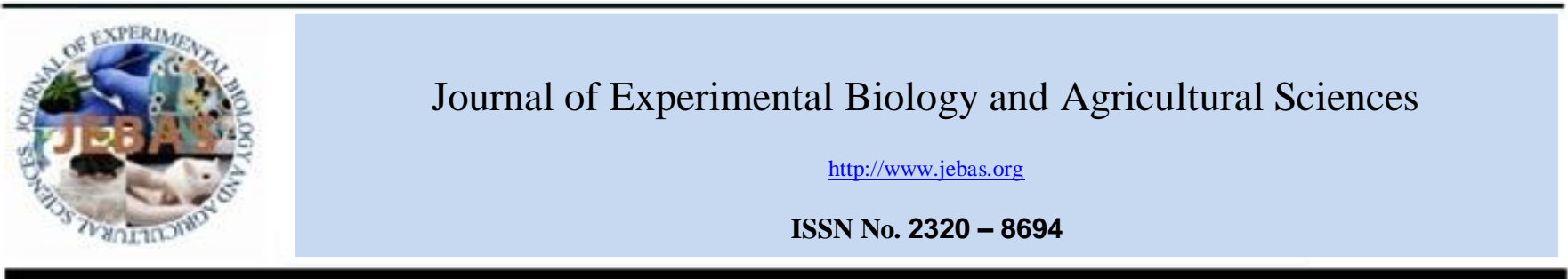

\title{
REVISITING EXTENSION SYSTEMS IN SAUDI ARABIA: EMERGING REASONS AND REALITIES
}

\author{
Mirza B. Baig ${ }^{* 1}$, Gary S. Straquadine ${ }^{2}$, F.O. Aldosari ${ }^{1}$ \\ ${ }^{1}$ Department of Agricultural Extension and Rural Society, College of Food and Agriculture Sciences, King Saud University, P.O. Box 2460, Riyadh 11451, Kingdom \\ of Saudi Arabia \\ ${ }^{2}$ Vice Chancellor, Utah State University - Eastern Campus, Price, Utah 84501 USA
}

Received - 29 April, 2017; Revision - 5 July, 2017; Accepted - 30 July, 2017

Available Online - 31 August, 2017

DOI: http://dx.doi.org/10.18006/2017.5(Spl-1-SAFSAW).S160.S164

\section{KEYWORDS}

Extension System

Training Programs

Greenhouse Crops

Marketing

Post-harvest Technologies

Climate Change

Water Resources

\begin{abstract}
Saudi Arabia is one of the world's most water stressed countries and hence at 'extreme risk'. The analyses presented by various scientists caution that the dual drivers of climate change and population growth will combine to put further stress on scarce water resources and affect the food security. To reduce the pressures on the diminishing and depleting water resources, the kingdom has put restriction on the planting of wheat, barley and fodder crops with high water requirements. Farmers have been encouraged to grow vegetable crops in the greenhouses by employing water-saving technologies. In the situation, the farmers need assistance related to green-house crop production and marketing of their produce. At the same time, the extension agents need trainings in the newly emerged situations. It would be important to bring all the stakeholders on the discussion table to devise strategies to address the emerging situation.
\end{abstract}

* Corresponding author

E-mail: mbbaig@ksu.edu.sa (Mirza B. Baig)

Peer review under responsibility of Journal of Experimental Biology and Agricultural Sciences.

Production and Hosting by Horizon Publisher India [HPI] (http://www.horizonpublisherindia.in/).

All rights reserved.
All the article published by Journal of Experimental Biology and Agricultural Sciences is licensed under a Creative Commons Attribution-NonCommercial 4.0 International License Based on a work at www.jebas.org.

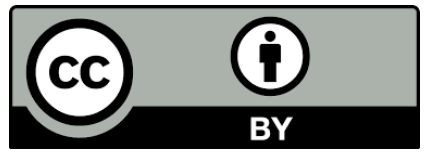




\section{Introduction}

Farming and farming business are becoming increasingly challenging and in the near future it would be difficult to keep the farmers productive and profitable due to roll back policy on agriculture and the other emerging realities impacting agriculture (Al-Shayaa et al., 2012; Baig and Straquadine, 2014). Agriculture is going to shrink and find its place in the green-houses (Hartmann et al., 2012). Extension workers are not ready to guide the greenhouse farmers and are not skilled and fully qualified to identify the problems and are unable to help them provide information to market their commodities. Agricultural produce and products need special packing and cold storage to increase the shelf-life of the perishable items. Whole production systems have been changed in the Kingdom. In the situation, complete overhauling of the agricultural policy seems imperative in order to tailor and devise the New Extension System to satisfy the emerging challenges. In this article, an effort has been made to identify the most prominent reasons, making it necessary to revisit the extension systems. In the light of the emerging challenges some workable strategies have been outlined. The purpose of this article to assist the planners and policy makers to make the improvement measures to keep the extension workers productive in the profession.

\section{Emerging Challenges make it essential to revisit the} extension systems

\subsection{Rural urban ratio}

Urbanization is a phenomenon that can be readily witnessed in the entire Arab world due to factors like high fertility rates, ruralurban migration, international labor migration, and the concentration of economic activity in urban areas (AFED, 2008). Rural culture and fabric is fading; rural unban ratio is becoming wider and wider every day; Rural areas and suburbs produce many products and herbal medicines and sustain small industries. Distortion of rural urban ratio would cause many impacts and exert pressures on the already over-populated and ever-growing neighboring towns; worsening the situation due to the continuous influx of foreign workers and experts.

\subsection{Subsidies are withdrawn}

Farmers in the past have been facilitated by offering them loans and subsidies on agro-chemicals and farm machinery to enable them grow more wheat. Almost free water supplies and inputs were made available at their door steps resultantly Saudi Arabia became the $6^{\text {th }}$ largest exporter of wheat. The Kingdom has adopted the policy to stop growing wheat, barley and fodder crops with high water requirements (Hartmann et al., 2012).

\subsection{Farmers need to raise high value crops that bring more prices and consume less water}

They need to avoid fodder (sorghum) and grain (barley) crops. There is a need to modify the cropping patterns keeping in view the suitability of the areas for a particular crop. Farmers are required to grow vegetables requiring less water in the greenhouses (FAO, 2017).

\subsection{ICT and e-extension and their applications in farming and extension}

Use of ICTs and their applications in farming and extension messages have become inevitable rather unavoidable. Farmers and agricultural extension staff need put them into their practice in their everyday business to keep them informed with the latest. Extension workers need to perform their functions and duties on ICT based knowledge. Both extension workers and farmers must equip themselves and realize the blessings of ICT (Al-Shayya et al, 2011)

2.5 More imports of agricultural commodities to satisfy food and feed needs and imposing bans on virtual water export

Saudi Arabia is now relying on food and feed resources of the neighboring countries capable of meeting the human and livestock needs of Kingdom. Such endeavors can successfully be met through the careful and wise negotiations made by the expert economists.

\subsection{Foreign workers in farming}

Expatriates have entered in the farming business creating special problems in farming business by practicing their own way of doing things ignoring the Arab culture and norms.

2.7 Wise and careful management of natural resources like water, lands, forests, wildlife are integral components of farming and they go hand in hand.

Neighboring forests and trees on the farms ameliorate harsh effects of weather conditions and improve the micro-climate. Forests and trees pose positive impacts on the farming and the growing crops and by saving them from the harmful effects of extreme temperatures and desiccating winds. There is a need to involve locals in managing the forests to conserve them and stop the expansion of agriculture farms at the expanse of forests. 
Participation of locals in managing the natural resources including forests seems a valid option. Rural people and the urban dwellers need to appreciate the natural resources and the landscape sustaining them without harming the existing ecosystems (AlSubaiee, 2016).

\subsection{Environmental challenges and pollution hazards}

Inappropriate and heavy applications of agricultural chemicals cause health hazards, environmental issues and pollution.

\subsection{Climate Change}

With the quest to enhance food self-sufficiency, Saudi Arabia faces serious challenges due to the factors like: aridity, limited cultivable land, scarce water resources and serious implications of climate change (AFED, 2014). Climate Change will have more pronounced effect on water resources and cropping systems. A small change in the temperature would mean a lot to agriculture. The kingdom has experienced prolonged droughts and floods due to climate change. Climate change has an impact on the frequency and intensity of extreme weather events. High variations of rainfall with an increase in flood events impact the Arab region. Severe floods affected Saudi Arabia and Yemen from 2008 to 2009 with an estimated total economic damage of approximately 1.3 billion USD (EM-DAT (www.emdat.be). Drought and climate change may significantly impact agriculture and change the landscape of the Arab region with severe implications for food security, rural-urban migration and social stability (FAO, 2008; El Mostafa and Al Assiri 2010).

2.10 Severe and serious Food security issues in the Arab Region are emerging

FAO (2015) identified the key food security challenge facing the Arab region due to the scarcity of arable land, aridity of climate, and acute scarcity of its water resources as well as policy challenges. FAO (2015) further revealed that agricultural productivity (e.g. measured by yields) is still quite low in Saudi Arabia; hence there may be some potential for improvement for both small and larger scale farmers. There is a need to collect data in this respect on the priority basis.

2.11 Low knowledge of farmers and extensionists on the use of agro-chemicals

They need to learn how to apply and when to apply insecticides in accurate quantities. Diseases in plants and crops need to diagnosed correctly and they must be cured and treated by applying through the correct and appropriate applications. Farm workers do not use protective covers and clothing and ignore the label precautions given at the containers. There is a need to use the right chemical for a particular crop. Every chemical does not work for all the insects-pests and diseases of all the crops.

\subsection{Greenhouse crop production}

The kingdom has entered in the new era of greenhouse crops production to save water and to overcome harsh climatic conditions. These crop production systems are new to the farmers. They need guidance right from planting to harvesting. They require information on post-harvest technologies, package, storage and marketing of the productions.

\subsection{Growers and the marketing of their productions}

Farmers are not the traders; to maximize their profits they are to be market-oriented by enhancing their marketing and business management skills.

\subsection{Post-harvest technologies to keep their produce fresh longer}

The subject of post-harvest technologies to over-come losses has not been taken seriously. To elevate the income levels, all possible efforts are needed to reach the maximum produce from farmers' fields to the markets.

\section{15 Farming on overseas on lands}

In order to address the decreasing domestic production and strong domestic demand, the country is encouraging agricultural investments abroad for products to be then shipped back to Saudi Arabia. This initiative targets wheat, rice, barley, yellow maize, soybeans and green forage (FAO, 2017). To conserve national water resources, the Kingdom is encouraging Saudi businessmen to acquire huge acreages of fertile irrigated lands with sufficient available water resources in Pakistan, Philippines, Sudan and other countries to ensure the continued supply of food crops in the Kingdom. At this juncture, it would be important for the extension to educate the business with various socio-cultural-economic and technical aspects.

\subsection{Previously covered fields with crops}

Previously extension has been engaged in converting more barren and dry lands into productive fertile lands to grow more grains from every single inch but now the focus is to bring less area 
under plow and consume as little water as possible. If the areas covered with agricultural crops would remain without crops cover, they may turn into barren lands and desertified. So we need to focus on technical aspects like: keep them covered, grow less but maintain high income levels; this is only possible when there is a balance between farming practices and economic opportunities created for the farmers to keep them in the farming business.

\section{17. Old extension education curriculum}

The present curriculum taught at the agricultural colleagues and universities seems outdated and would not be addressing the merging challenges. Therefore it is important to include the subjects of: environmental challenges, natural resource management, economic opportunities, role of ICT in farming, applications of agrochemicals, composting and manures, organic farming, water conservation technologies etc.

\section{18. Saudi Arabia is signatory to WTO and other treaties}

Saudi Arabia has signed several international treaties. Farmers and the extension agents are to be furnished with the basics of the treaties.

\section{Strategies to improve the situation}

Extension education needs to develop plans for the farmers on the wise and economic use of water for various crops in various ecological zones and design and launch training programs for the farmers and extensionists. All the policy makers and planners need to join hands with the extension staff agronomists; irrigation engineers and water experts; sociologists, entomologists, plant pathologists; post-harvest technologists; marketing experts and the economists to devise a vibrant but completely a brand new extension system based on the comprehensive policy and an integrated strategy to keep the farmers in the farming business.

Intensive trainings for the extension staff would be required to keep them abreast and equip them with the solutions to the recently and newly emerged challenges that were not faced before. For example, extension staff needs immediately trainings and upgrade their skills on the biological control of major insects and mites using natural enemies in greenhouses' vegetable production, mites and Lepidoptera pests on date palm in Kingdom of Saudi Arabia (FAO, 2011). It is important to make immediate changes in the existing curriculum used in the degree programs taught at the universities.
- Grow more with less water by employing modern irrigation systems e.g. drip irrigation;

- Market oriented extension to maximize profits to keep farmers in farming business;

- Extension on technologies starting from farm to fork to experience the least food wastage

- Extension Education for enhancing shelf-life of agricultural commodities

- Extension to move towards organic farming as it the part of sustainable agriculture;

- Extension for green house vegetables and fruit productions;

- Extension for preventing presently fertile lands turning into barren lands in case of bringing less lands under cultivation; otherwise more environmental issues will emerge/arise;

- Extension for efficient and comparatively less expansive imports as we would be producing less in KSA in future;

- Extension lessons from bio-technologists tailoring crops with less water requirements bringing them to the farmers;

- Trainings of farmers and all the stake-holders in the changing scenarios

- Making farmers realize the importance of roll-back policy -moving back from self-sufficiency to subsistence farming;

- Extension Education is needed to enable the farmers to launch the overseas farming ventures successfully.

\section{Conclusions and recommendations}

Farming business has changed significantly. We need to make the farmers and extensionists as the scientists and the economists, experts on marketing. It is the time to bring all the stake-holders under one umbrella to redefine the roles of the extensionists and chalk out their responsibilities. Extension agents would not be able to perform their duties in the changing scenario. They are to be prepared through extensive and vibrant training programs in the areas identified in the article particularly in greenhouse production technologies to undertake their new roles and responsibilities effectively and efficiently.

\section{Acknowledgements}

Authors are extremely thankful to the Deanship of the Scientific Studies at the King Saud University, Saudi Arabia for its support. 


\section{References}

AFED (2008). 2008 Arab Forum for Environment and Development (AFED) Published with Technical Publications and Environment \& Development magazine P.O. Box 113-5474, Beirut, Lebanon

AFED (2014). Arab Environment: Food Security. Annual Report of the Arab Forum for Environment and Development, 2014; A. Sadik, M. El-Solh and N. Saab (Eds.); Beirut, Lebanon. Technical Publications.

Al-Shayaa, MS., Al Shenifi MS and Al Hadi, HS AL Abdu. (2011). Constraints to Use Computers among Agricultural Extension Workers in Riyadh and Qaseem Regions of Saudi Arabia. The Journal of Animal \& Plant Sciences, 21(2): 2011, Page: 264-268

Al-Shayaa MS, Baig MB, Straquadine GS (2012) Agricultural extension in the Kingdom of Saudi Arabia: difficult present and demanding future. Journal of Animal Plant Science 22 : 239-246.

Al-Subaiee, FS (2016). Local Participation in Woodland Management in the Southern Riyadh Area: Implications for Agricultural Extension. Geographical Review 105 (4): 408-428, October 2015

Baig MB, Straquadine GS (2014) Sustainable Agriculture and Rural Development in the Kingdom of Saudi Arabia: Implications for Agricultural Extension and Education. In: Behnassi M, Syomiti M, Gopichandran R, KiritShelat (Eds.), Climate Change: Toward Sustainable Adaptation Strategies. Springer Science +Business Media B.V., Dordrecht. Netherlands. Pp 101-116. DOI
10.1007/978-94-017-8962-2_7.

Hartmann, M., Khalil S., Bernet T., Ruhland F., and Al Ghamdi A. 2012. Organic Agriculture in Saudi Arabia. Sector Study 2012 Deutsche Gesellschaft für Internationale Zusammenarbeit GIZ $(\mathrm{GmbH})$, Saudi Organic Farming Association (SOFA), Research Institute of Organic Agriculture (FiBL) \& Ministry of Agriculture of Saudi Arabia (MoA), Riyadh, KSA 2012

El Mostafa D, Al Assiri A (2010) Response to climate change in the Kingdom of Saudi Arabia.FAO-RNE, Cairo.

Food and Agricultural Organization (FAO), 2008. Climate Change: Implications for Agriculture in the Near East [NERC/08/INF/5] Synopsis of the Twenty-Ninth FAO Regional Conference for the Near East held in Cairo, Egypt, 1-5 March 2008. Rome: FAO

FAO (2011) FAO Technical Cooperation Programme, Achievements, The Technical Cooperation between Kingdom of Saudi Arabia and Food and Agriculture Organization of the United Nations (FAO), FAO Office in Riyadh, Kingdom of Saudi Arabia, July 2011

FAO (2015). Regional Coordination Mechanism (RCM) Issues Brief for the Arab Sustainable Development Report Sustainable Agriculture and food secuirty in the Arab Region. Available at: http://css.escwa.org.lb/SDPD/3572/Goal2.pdf

FAO (2017). Country Brief - Saudi Arabia. GIEWS - Global Information and Early Warning System. Available at: http://www.fao.org/giews/countrybrief/country.jsp?code=SAU\&la $\mathrm{ng}=\mathrm{en}$ 